\title{
Notas sobre as escolas de samba e a pandemia do novo coronavírus
}

\author{
LUCAS BÁRTOLO \\ Universidade Federal do Rio de Janeiro, Rio de Janeiro, Rio de Janeiro, Brasil \\ bartolo.lucas@hotmail.com \\ JoÃo Gustavo Martins Melo De SOUSA \\ Universidade do Estado do Rio de Janeiro, Rio de Janeiro, Rio de Janeiro, Brasil \\ gugamelo22@gmail.com
}

DOI 10.11606/issn.2316-9133.v29isuplp194-203

\begin{abstract}
resumo Este artigo é um relato a quatro mãos sobre os efeitos em curso da pandemia do novo coronavírus no ciclo anual de produção do carnaval carioca. Depois de apresentar algumas ações de enfrentamento à crise econômica e sanitária articuladas pelas escolas de samba junto às suas comunidades, veremos como as atividades recreativas e culturais estão sendo adaptadas ao contexto de isolamento social, com a virtualização de eventos e performances que permitem a manutenção do calendário carnavalesco. Por fim, discutiremos como o mundo do samba está construindo e legitimando o debate sobre quando e como acontecerão os próximos desfiles. Com isso, não pretendemos inventariar desafios e propor soluções para o carnaval em tempos críticos, mas relatar como as escolas e os sambistas estão atravessando este período liminar, e o que isso nos permite pensar sobre essa expressão singular da cultura popular.
\end{abstract}

palavras-chave Escola de samba; carnaval; pandemia; ritual; cultura popular.

\section{Notes on samba schools and the coronavirus pandemic}

abstract This text brings an account of the ongoing effects of the new coronavirus pandemic on the annual production cycle of the Rio's carnival. After presenting some actions to face the economic and health crisis articulated by the samba schools with their communities, we will see how recreational activities are being adapted to the context of social isolation, highlighting the maintenance of the carnival calendar by virtualizing events and performances. Finally, we will discuss how the samba people are building and legitimizing the debate about when and how the next parades will take place, highlighting some economic and symbolic aspects. With this, we do not intend to inventory challenges and propose solutions for carnival in critical times, but to report how schools and their 
BÁRTOLO; SOUSA | Notas sobre escolas de samba e a pandemia do novo coronavírus |195

agents are going through this liminal period, and what this allows us to think about this singular expression of popular culture.

keywords samba school; carnival; pandemic; ritual; popular culture.

\section{De las escuelas de samba y la pandemia del coronavírus}

resumen Este texto presenta una explicación de los efectos continuos de la pandemia en el ciclo de producción anual del carnaval de Río. Después de presentar algunas acciones para enfrentar la crisis económica y de salud articulada por las escuelas de samba con sus comunidades, veremos cómo las actividades recreativas se están adaptando al contexto de aislamiento social, destacando el mantenimiento del calendario de carnaval mediante la virtualización de eventos y actuaciones. Finalmente, discutiremos cómo el mundo de la samba está construyendo y legitimando el debate sobre cuándo y cómo tendrán lugar los próximos desfiles. Con esto, no pretendemos inventariar desafíos y proponer soluciones para el carnaval en tiempos críticos, sino informar cómo las escuelas de samba y sus agentes están pasando por este período preliminar, y qué nos permite pensar sobre esta expresión singular de la cultura popular.

palabras clave escuela de samba; carnaval; pandemia; ritual; cultura popular.

\section{Introdução}

Este artigo é um relato a quatro mãos sobre os impactos da pandemia do novo coronavírus no ciclo de produção do carnaval carioca ${ }^{1}$. Aqui, buscamos compreender como esse processo ritual (TURNER, 1974; CAVALCANTI, 2006) vem sendo reconfigurado nesse contexto crítico (DAS, 1995; KAPFERER, 2010; MENEZES, 2020). Nosso intuito é menos o de inventariar desafios e propor soluções para a realização da festa, do que perceber como as escolas de samba e os sambistas estão atravessando esse período liminar.

Ao abordar o processo ritual carnavalesco em um período marcado pela doença, perda de postos de trabalho e restrição do convívio social, jogaremos luz tanto para atuação das escolas na tentativa de redução da vulnerabilidade de suas comunidades de origem, quanto para as dimensões criativas da adaptação do calendário festivo. Sugere-se, assim, uma chave de compreensão que enrede a potência associativa direcionada para ações reconhecidas como solidárias, e o lúdico como forma de ritualização e atribuição de sentido no contexto crítico da pandemia.

$\mathrm{O}$ artigo está estruturado em três partes. Primeiro, apresentaremos algumas dessas ações solidárias a partir do relato de Mestre Fafá, da Acadêmicos do Grande Rio. Em seguida, veremos como as atividades recreativas estão sendo adaptadas a esse contexto, destacando a virtualização de eventos e performances. Por fim, discutiremos como o mundo do samba está construindo e legitimando o debate sobre quando e como acontecerão os próximos desfiles.

\footnotetext{
${ }^{1}$ Este texto é dedicado à memória dos sambistas e artistas do carnaval vitimados pela COVID-19.
} 
BÁRTOLO; SOUSA | Notas sobre escolas de samba e a pandemia do novo coronavírus |196

\section{Carnaval em quarentena}

Pelo menos desde 2017, quando Marcelo Crivella, bispo licenciado da Igreja Universal do Reino de Deus, assumiu a prefeitura do Rio de Janeiro, as escolas de samba atravessam um período de crise marcado pela desestabilização política associada a um quadro global de escassez de recursos. Notório crítico dos festejos momescos e das expressões associadas às tradições afro-brasileiras, o prefeito adotou progressivamente medidas restritivas em relação à festa, retirando o apoio financeiro do município aos desfiles. As manifestações contrárias ao prefeito vieram acompanhadas de uma autocrítica das agremiações. Alguns dirigentes, que haviam apoiado Crivella nas eleições, passaram a cogitar o cancelamento dos desfiles ${ }^{2}$.

Com o rompimento entre a prefeitura do Rio e o carnaval carioca durante a crise econômica, desenhou-se um movimento de reconstrução dos vínculos comunitários e identitários pelas agremiações, que teriam sido afrouxados ou esquecidos nas últimas décadas, quando as escolas teriam priorizado as relações comerciais estabelecidas em torno do evento carnavalesco ${ }^{3}$. Essa retomada estaria se dando fundamentalmente a partir dos enredos, agora definidos menos pelas negociações com empresas interessadas na exibição de suas marcas do que pelo acionamento de um universo simbólico caro a sua comunidade, destacando-se as temáticas religiosas (MENEZES, BARTOLO, 2019).

Das crises econômicas e políticas, chegamos, em meados de março, à crise sanitária que exigiu o isolamento social, ironicamente coincidindo com o período da quaresma. Ao invés das premiações, definições de enredo e retomada das feijoadas, atividades típicas desse período do ano carnavalesco, as escolas de samba iniciaram uma intensa mobilização em ações articuladas de enfrentamento à pandemia, que tentam frear o agravamento das precárias condições de existência em suas comunidades, onde a letalidade do vírus já se mostra maior ${ }^{4}$.

A estrutura do sambódromo está sendo utilizada pela Prefeitura para acolher pessoas em situação de rua, enquanto os barracões e as quadras de ensaio ganharam novas funções: a confecção de equipamentos de proteção e distribuição de cestas básicas. Máscaras e aventais estão sendo produzidos pelas equipes de costura dos barracões sob coordenação da Liga das Escolas de Samba, e orientação de profissionais do Hospital Universitário da UFRJ e da Fiocruz. Esses itens são destinados tanto aos trabalhadores do sistema de saúde quanto à população em geral. Boa parte das cestas básicas estão chegando às comunidades por meio de redes de solidariedade que se formam pela internet, articuladas por membros das escolas, cujas quadras servem de ponto de arrecadação e distribuição das doações. Por meio de

\footnotetext{
${ }^{2}$ Esse debate foi materializado no carnaval mangueirense de 2018, "Com dinheiro ou sem dinheiro, eu brinco", assinado por Leandro Vieira, e analisado em Menezes e Bártolo (2019), Bonfim (2019) e Oliveira Junior (2019).

${ }^{3}$ Para uma avaliação interna desse cenário, ver Valença (2019).

${ }^{4}$ De acordo com reportagem do jornalista Caio Briso (2020) registra-se a alta mortalidade pela COVID-19 entre sambistas como consequência da vulnerabilidade das periferias brasileiras durante a pandemia.
} 
interlocutores e da imprensa carnavalesca, registramos cerca de 70 campanhas solidárias articuladas pelas agremiações e outras associações de sambistas entre os meses de abril e maio. $^{5}$

A potência associativa e criativa das comunidades articuladas em torno das escolas de samba, evidenciada anualmente na confecção dos desfiles, agora é mobilizada em redes de proteção e solidariedade contra a epidemia e a fome. Assim como terreiros, igrejas, associações de moradores e projetos sociais, as escolas de samba integram uma complexa rede de sociabilidades nos territórios em que estão localizadas e demonstram uma capacidade de enraizamento que permite alcançar a ponta de uma cadeia onde diversos agentes do Estado não chegam. Essa capacidade passou a ser mobilizada pelo governo estadual dois meses após o início da pandemia, quando foi estabelecida uma parceria com as agremiações para mapear os casos subnotificados de COVID-19 por meio de questionários digitais a serem preenchidos por suas comunidades.

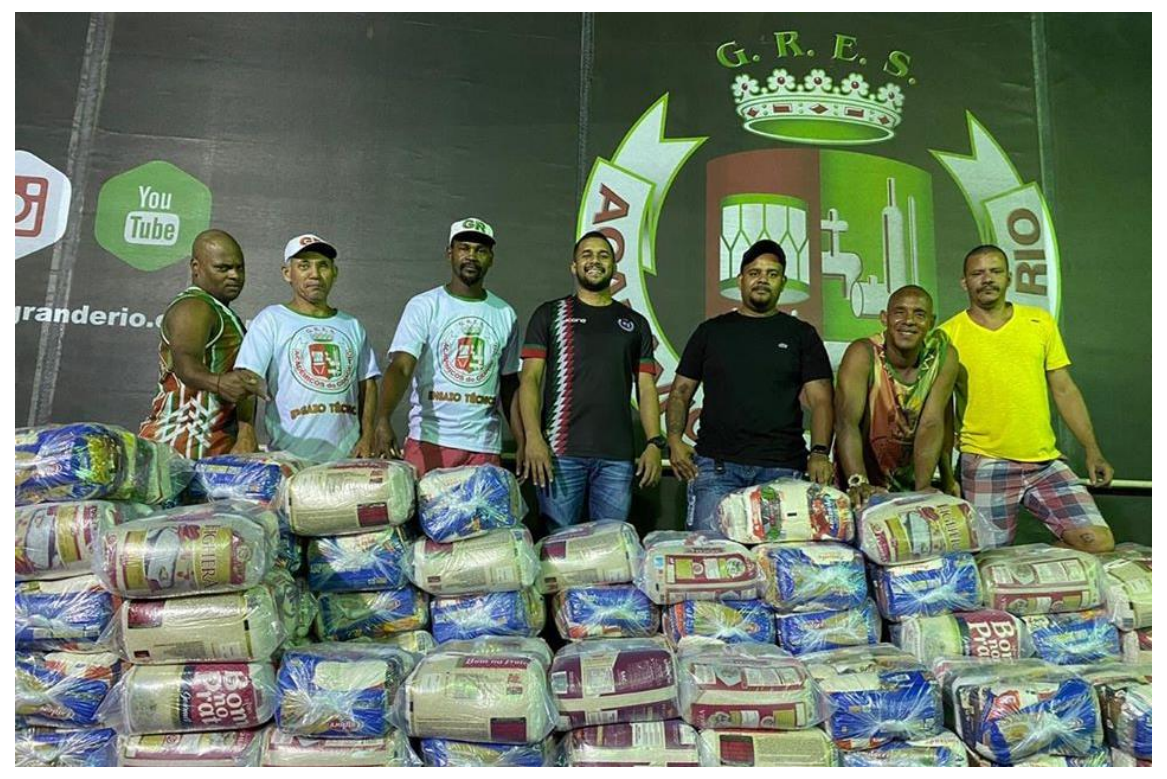

Figura 1. Adriano, Pará, Léo, Fafá, Clayton, Sidney e Robinho, integrantes da equipe à frente das ações solidárias da Grande Rio. Fonte: Facebook Grande Rio, 15 de abril de 2020.

A Acadêmicos do Grande Rio, de Duque de Caxias, é um caso exemplar da articulação entre a capacidade de enraizamento e o papel de mediação que as escolas desempenham com outras camadas da sociedade. Terceira maior cidade do Rio de Janeiro, com 920 mil habitantes, mas a $48^{\circ} \mathrm{em} \mathrm{IDH}^{6}$, Caxias é a que registra mais óbitos por COVID-

\footnotetext{
${ }^{5}$ Fonte: \#SAMBACONTRAPANDEMIA - Portal SRZD. Disponível em <https://www.srzd.com/tag/ sambacontrapandemia/ $>$, acesso em 21 de maio de 2020.

${ }^{6}$ Dados do Atlas Humano do Desenvolvimento de 2013. Disponível em: http://www.atlasbrasil.org.br/ 2013/pt/perfil_m/duque-de-caxias_rj
} 
19 no estado depois da capital, embora seja o quarto município em casos confirmados. Os números são imprecisos considerando as subnotificações, mas evidenciam a alta mortalidade pela doença que acompanha Caxias desde o início da pandemia, quando o prefeito Washington Reis (MDB) negava a gravidade da doença e afirmava que as igrejas evangélicas deveriam permanecer abertas porque "a cura virá de lá". Em 03 de abril, após a primeira morte registrada no município, Reis decretou as medidas de restrição do convívio social e se internou em hospital privado na zona sul da capital após testar positivo para COVID-19. Naquela semana, a Grande Rio começava a mobilizar redes de solidariedade para apoiar pelo menos quatro localidades que formam a sua base comunitária: Parque Centenário, Mangueirinha, Corte 8 e Morro do Sapo.

Os relatos chegam através do mestre de bateria Fabrício Machado de Lima (Fafá), jovem liderança caxiense que está na linha frente das ações articuladas pela Grande Rio. Em 04 de abril, a escola doou mil cestas básicas com recursos próprios e adaptou a sua quadra de ensaios para confecção de máscaras de tecido e protetores faciais hospitalares. A partir de então, a Grande Rio, por vezes chamada de "escola de celebridades", alcunha que acusaria uma perda de laços comunitários e identitários, acionou uma rede de artistas e influenciadores digitais que em um mês e meio arrecadou quase dez toneladas de mantimentos. Os números são expressivos de uma bem sucedida mediação, que também levou à reaproximação comunitária e à atualização do papel social da agremiação, ainda que, frente à situação de vulnerabilidade agravada pela pandemia, sejam ações paliativas. Por Whatsapp, Fafá nos relatou:

A gente buscou ouvir as pessoas, mapear os lugares mais vulneráveis, tentar ir de casa em casa, pessoa a pessoa, mas Caxias tem um milhão de habitantes, não conseguimos atender a todos. O que tentamos aqui é dar uma sobrevida de um mês, um mês e meio para algumas famílias. É muito triste eu negar uma cesta básica para um pai de família, uma mãe de família que nos procura aqui na quadra porque eu não tenho mais ou as que eu tenho já estão comprometidas para pessoas que moram em locais distantes. Semana passada entregamos duas mil cestas básicas em casas de pessoas que não têm nem saneamento básico. Eu fui à casa de um ritmista meu e ele chorou porque não esperava a cesta básica, mas eu soube da situação dele, que ele estava passando necessidade. Aquilo acabou comigo. [...] Sabemos o papel da nossa escola perante a nossa comunidade. O que estamos tentando fazer é retribuir um pouquinho de carinho que as pessoas têm com a gente, em nossos ensaios. Essa campanha é para tentar dar um pouquinho de esperança para as pessoas, dar uma sobrevida enquanto essa pandemia não passa, mas a gente sabe que é difícil (Mestre Fafá, 14 de abril de 2020). 
BÁRTOLO; SOUSA | Notas sobre escolas de samba e a pandemia do novo coronavírus |199

Enviado da ponta dessa rede de ajuda, o relato joga luz a uma dimensão cotidiana da pandemia na qual o agravamento da desigualdade social se faz sensível e provoca sofrimento, tanto pela doença, quanto pela insegurança alimentar. Para além das ações diretas e imediatas de redução da vulnerabilidade das comunidades, ou associadas a elas, as escolas tentam adaptar suas atividades recreativas ao contexto de isolamento social. A virtualização dos eventos e performances, desde feijoadas com rodas de samba até lançamento de enredos, nos quais mobiliza-se o público para campanhas solidárias e articula-se o mundo do samba (LEOPOLDI, 2010), possibilita outras formas de dar continuidade ao calendário anual do carnaval.

Obedecendo e incentivando o distanciamento social, essas atividades se tornaram sistemáticas a partir do dia 23 de abril, quando algumas escolas transmitiram pelo Facebook rodas de samba virtuais e distribuíram quentinhas de feijoada em suas comunidades, atualizando a tradição de festejar os padroeiros São Jorge e Ogum. No mesmo dia, a Unidos do Viradouro lançou o seu enredo para o próximo carnaval. A escola anuncia tradicionalmente os seus enredos a cada 23 de abril, reunindo milhares de torcedores e componentes na quadra de ensaios, no bairro do Barreto, em Niterói. Neste ano, o evento foi transmitido da sala de estar do cantor Zé Paulo Sierra, que interpretou sambas de enredo clássicos do repertório da escola, acompanhado por um cavaquinista. Com duração de 1h40min, também foram exibidos depoimentos de integrantes da Viradouro, e os carnavalescos apresentaram e debateram a proposta de enredo, dando um caráter cerimonial à transmissão.

Em 3 de maio, foi transmitida no YouTube a "Feijoada do Salgueiro", com apresentações de intérpretes da escola. No sábado seguinte, 10 de maio, a Beija-Flor de Nilópolis, articulada com outras seis escolas, produziu em seu barracão a "Live do Samba" um evento mais estruturado, seguindo o formato emergido nas apresentações dos cantores sertanejos, em que as transmissões caseiras dão lugar a shows com complexa produção desde o cenário até a grade de programação. Destaca-se nesse modelo a articulação entre as dimensões filantrópica e publicitária, com exibição de marcas patrocinadoras e campanhas de doação online. Na live, que teve 184 mil visualizações ao vivo, foram arrecadadas mais de 60 toneladas de alimentos.

A virtualização de eventos e performances abre um leque de questões que ultrapassam os limites deste texto. No caso das escolas de samba, elas reaquecem debates anteriores à pandemia sobre modelos de gestão e atualizam as tensões constitutivas da festa entre tradição e espetáculo. Ao mesmo tempo, ao possibilitarem a mobilização virtual do corpo social das agremiações em torno de eventos que marcam o seu calendário, sinalizam possibilidades criativas de realização do processo ritual carnavalesco (CAVALCANTI, 2006) - além de redimensionar as agendas de pesquisa e o formato dos nossos trabalhos de campo. Embora não ofereçam respostas, essas ações abrem o debate sobre quando e como as escolas desfilarão, uma questão absolutamente legítima que convive com a preocupação prioritária de salvar vidas. 


\section{Perspectivas em meio ao caos}

Com o agravamento da situação sanitária no país, é difícil projetar com clareza as estratégias a serem adotadas para que os sambistas possam começar a preparar o próximo desfile. $\mathrm{O}$ mundo do samba, especialmente por meio da imprensa especializada na cobertura das escolas de samba, tem se dedicado a construir diariamente, acompanhando a instabilidade de nossa conjuntura, o debate em torno desse tema. É uma iniciativa que se coloca como contraponto a alguns discursos defendidos no debate público pós-decreto da pandemia de que não se deve pensar em carnaval em um momento de grande sofrimento e perdas. Trata-se também de uma defesa contra as acusações de que o vírus teria se disseminado no Brasil durante o carnaval.

Nos fóruns carnavalescos surgem questões sobre calendário, criação artística e os impactos na economia da festa, além das dimensões políticas e sanitárias. Está na pauta, por exemplo, a indissociabilidade ou não dos desfiles em relação ao carnaval datado pelo calendário cristão. Para além da dimensão cosmológica, abre-se um debate sobre o circuito das festas populares e da troca e circulação de coisas e pessoas entre elas. Notoriamente, a mão-de-obra especializada que circula entre o desfile das escolas de samba em fevereiro ou março e o Festival Folclórico de Parintins, em junho (SOUSA, 2018). Outro ponto bastante debatido são os desafios colocados pela crise em sua escala global e a dependência dos desfiles, em seu formato atual, de produtos e materiais chineses, além do problema cambial que se agrava.

Em maio deste ano, o Museu do Samba publicou o novo número de sua revista, editada por Nilcemar Nogueira, diretora do museu e ex-secretária de cultura da prefeitura de Crivella. A Samba em Revista reúne em sua nova edição textos de sambistas, pesquisadores e gestores culturais para debater "aspectos políticos, econômicos, sociais e religiosos do Carnaval em tempos de crise", abrangendo os desafios institucionais e financeiros enfrentados pelas escolas nos últimos anos, tendo como marco o corte na subvenção municipal ao carnaval. A crise em torno da COVID-19 é tratada especificamente em um texto do economista Marcel Balassiano, da Fundação Getúlio Vargas, que analisa:

Sobre a importância da 'indústria' do carnaval para a economia, aqueles menos acostumados com o 'mundo do samba' podem pensar que o carnaval acontece somente em fevereiro (ou março, dependendo do ano). Mas não, durante o ano inteiro ocorrem etapas e eventos que chegam finalmente no ápice, que é o desfile na Marquês de Sapucaí. [...] Quando tudo isso passar (e vai passar!), o carnaval e em especial as escolas de samba terão um papel muito importante na retomada da economia do Rio de Janeiro no pós-crise. O turismo nacional, num primeiro momento de começo de retomada do setor, poderá ser impactado positivamente. (BALASSIANO, 2020, p.22) 
Tomando os desfiles como um fato social total (MAUSS, 2003), como a própria edição da revista sugere, percebemos a preeminência econômica tanto na construção de argumentos para legitimar o carnaval, quanto na busca por perspectivas para se pensar a festa no pós-pandemia. Gostaríamos ainda de chamar atenção para as dimensões simbólicas e festivas desse processo, destacando a importância do anúncio de um enredo nesse período liminar.

\section{"Não há tristeza que possa suportar tanta alegria"}

Como mencionamos, a atual campeã do carnaval carioca, Unidos do Viradouro, lançou online o seu enredo para 2021. Intitulado "Não Há Tristeza que Possa Suportar Tanta Alegria”, o enredo tematiza o carnaval de 1919, o primeiro depois da Primeira Guerra Mundial e da devastadora gripe espanhola. O título refere-se à marchinha homônima lançada naquele carnaval, que se não foi o maior de todos os tempos, como é lembrado pelos cronistas, foi aquele em que o samba assumiu o protagonismo da festa e que nos apresentou o Cordão do Bola Preta. Escritores, como Nelson Rodrigues, relatam em suas memórias que o motivo para tamanha euforia era que a cidade não suportava mais chorar a dor das perdas causadas pela epidemia que assolou o mundo e matou entre 50 e 100 milhões de pessoas em diversos países. No Rio de janeiro, então com um milhão de habitantes, estima-se que 600 mil foram contaminados e, destes, 15 mil morreram. Mal acabara de contar os mortos pelo vírus Influenza, o Rio de Janeiro saiu às ruas para se esbaldar nos salões, nos clubes, no calor das ruas, nos grandiosos desfiles das grandes sociedades, nos cortejos motorizados dos corsos, como se fosse o último Carnaval das suas vidas, brincando com estandartes e músicas que aludiam aos fatos da dolorosa epidemia (SANTOS, 2006, p. 139).

Equivoca-se quem lê como normalização insensível o lançamento de um enredo para o próximo carnaval, em plena pandemia que suspende a temporalidade rotineira, desestabiliza as normas sociais e, no limite, nos despessoaliza em números de contaminados e mortos, destituídos dos ritos de morte. Pensar e planejar o carnaval, do qual não se sabe quando nem como acontecerá. Parece-nos um esforço dos sambistas e artistas carnavalescos em dar continuidade a um processo ritual pelo qual constroem a principal manifestação simbólica coletiva do país. O enredo da Viradouro coloca a atual pandemia em perspectiva histórica e abre a possibilidade esperançosa de carnavalizá-la, lembrando-nos que os sambistas e populares que frequentavam a Festa da Penha no século passado elaboraram e atribuíram sentido às dores e perdas daquele período transformando a espanhola em marchinha.

Em meio a tantas incertezas, o impulso humano de se expressar e festejar é incorporado à urgência de sobreviver à pandemia. As escolas de samba reforçam seus laços afetivos e comunitários construindo redes de ajuda, ao mesmo tempo em que restituem o direito de ritualizar e atribuir sentido ao mundo, imaginando cenários a partir de uma nova realidade que já se impõe. Habituado ao ciclo anual de morte e renascimento, os sambistas e demais agentes do carnaval têm empreendido a renovação das escolas de samba, que morrem 
e ressurgem desde a sua criação. É dos escombros do real que poderá nascer o sonho do próximo desfile.

\section{Referências bibliográficas}

BALASSIANO, Marcel. (2020). Crise do Coronavírus ressalta mais ainda a importância das escolas de samba. Samba em revista. Carnaval em tempos de crise. Rio de Janeiro: ano 12, no 9, maio, 2020, p. 20-23.

BONFIM, Evandro de Sousa. (2019). "Só Momo expulsa o Crivella das pessoas”: Críticas não-verbais e carnavalescas à Prefeitura do Rio de Janeiro. Policromias. Vol. 4, n. 1.

BRISO, Caio Barretto. "Coronavirus leaves world of Brazilian samba in mourning". The Guardian. Rio de Janeiro, 8 de maio de 2020. Disponível em <https://www.theguardian.com/world/2020/may/08/coronavirus-leaves-world-ofbrazilian-samba-in-mourning $>$, acesso em 09 de maio de 2020.

CAVALCANTI, Maria Laura Viveiros de Castro. (2006). Carnaval Carioca: dos bastidores ao desfile. Rio de Janeiro: Editora UFRJ.

DAS, Veena. (1995). Critical Events: An Anthropological Perspective on Contemporary India. New Delhi: Oxford University Press.

KAPFERER, Bruce. (2010). In the event: Toward an anthropology of generic moments. Social Analysis, v. 54, n. 3, p. 1-27.

LEOPOLDI, José Sávio. (2010). Escola de samba, ritual e sociedade. Rio de Janeiro: Editora UFRJ.

MAUSS, Marcel. (2003). "Ensaio sobre a dádiva. Forma e razão da troca nas sociedades arcaicas". In Sociologia e Antropologia. São Paulo: CosacNaify, p. 183-314.

MENEZES, Renata de Castro. (2020). "Caos, crise e a etnografia das escolas de samba do Rio de Janeiro”. Hawò, v. 1, p. 63885-38.

MENEZES, Renata de Castro; BÁRTOLO, Lucas. (2019). "Quando a devoção e o carnaval se encontram". In: PROA - revista de Antropologia e Arte. Vol.9, n.1. p.96-121

OLIVEIRA JUNIOR, Mauro Cordeiro de. (2019). Carnaval e poderes no Rio de Janeiro: escolas de samba entre a LIESA e Crivella. Dissertação (Mestrado em Ciências Sociais) Departamento de Ciências Sociais, Pontifícia Universidade Católica do Rio de Janeiro, Rio de Janeiro.

SANTOS, Ricardo Augusto dos. (2006). “O Carnaval, a peste e a 'espanhola”. História, Ciências, Saúde-Manguinhos, 13(1). Rio de Janeiro.

SOUSA, João Gustavo Martins Melo de. (2018). “'É Garantido, é Caprichoso, é Carnaval: Parintins em desfile no Carnaval de 1998 do G.R.E.S. Acadêmicos do Salgueiro. In: Policromias, v.3, p. 160-176

TURNER, Victor. (1974). O processo ritual: estrutura e anti-estrutura. Petrópolis: Vozes.

VALENÇA, Rachel. (2019). "Em busca de uma saída”. Portal Sidney Valença. Rio de Janeiro, 2 de julho de 2019, disponível em <https://www.srzd.com/colunas/rachel-valenca/embusca-de-uma-saida-por-rachel-valenca/>, acesso em 23 de maio de 2020 
BÁRTOLO; SOUSA | Notas sobre escolas de samba e a pandemia do novo coronavírus |203

sobre os autores

\section{Lucas Bártolo}

Mestre pelo Programa de Pós-graduação em Antropologia Social do Museu Nacional da Universidade Federal do Rio de Janeiro, onde atualmente cursa o doutorado. Possui graduação em Ciências Sociais, também pela UFRJ.

\section{João Gustavo Martins Melo de Sousa}

Doutorando e mestre em Artes pelo Programa de PósGraduação em Artes da Universidade do Estado do Rio de Janeiro (PPGARTES/UERJ). Graduado em Comunicação Social (jornalismo) pela Universidade Federal do Ceará. Atualmente é bolsista FAPERJ/Qualitech.

Recebido em 28/05/2020 Aceito para publicação em 19/08/2020 